\title{
Characterization and Determination of Nanoparticles in Commercial Processed Foods
}

\author{
Jin Yu (D, Ye-Rin Jeon, Ye-Hyun Kim, Eun-Been Jung and Soo-Jin Choi * \\ Division of Applied Food System, Major of Food Science \& Technology, Seoul Women's University, \\ Seoul 01797, Korea; ky5031@swu.ac.kr (J.Y.); yrjeon0715@swu.ac.kr (Y.-R.J.); ye4978@swu.ac.kr (Y.-H.K.); \\ ebe2@swu.ac.kr (E.-B.J.) \\ * Correspondence: sjchoi@swu.ac.kr; Tel.: +82-2-970-5634; Fax: +82-2-970-5977
}

Citation: Yu, J.; Jeon, Y.-R.; Kim

Y.-H.; Jung, E.-B.; Choi, S.-J.

Characterization and Determination

of Nanoparticles in Commercial

Processed Foods. Foods 2021, 10, 2020

https://doi.org/10.3390/

foods 10092020

Academic Editors: Antonello Santini, Giacomo Dugo and Nicola Cicero

Received: 29 July 2021

Accepted: 25 August 2021

Published: 28 August 2021

Publisher's Note: MDPI stays neutral with regard to jurisdictional claims in published maps and institutional affiliations.

Copyright: (c) 2021 by the authors. Licensee MDPI, Basel, Switzerland. This article is an open access article distributed under the terms and conditions of the Creative Commons Attribution (CC BY) license (https:// creativecommons.org/licenses/by/ $4.0 /)$

\begin{abstract}
A wide variety of foods manufactured by nanotechnology are commercially available on the market and labeled as nanoproducts. However, it is challenging to determine the presence of nanoparticles (NPs) in complex food matrices and processed foods. In this study, top-downapproach-produced (TD)-NP products and nanobubble waters (NBWs) were chosen as representative powdered and liquid nanoproducts, respectively. The characterization and determination of NPs in TD-NP products and NBWs were carried out by measuring constituent particle sizes, hydrodynamic diameters, zeta potentials, and surface chemistry. The results show that most NBWs had different characteristics compared with those of conventional sparkling waters, but nanobubbles were unstable during storage. On the other hand, powdered TD-NP products were found to be highly aggregated, and the constituent particle sizes less than $100 \mathrm{~nm}$ were remarkably observed after dispersion compared with counterpart conventional bulk-sized products by scanning electron microscopy at low acceleration voltage and cryogenic transmission electron microscopy. The differences in chemical composition and chemical state between TD-NPs and their counterpart conventional bulk products were also found by X-ray photoelectron spectroscopy. These findings will provide basic information about the presence of NPs in nano-labeled products and be useful to understand and predict the potential toxicity of NPs applied to the food industry.
\end{abstract}

Keywords: top-down-approach-produced nanoparticle; nanobubble; nano-labeled processed foods; determination; particle size; surface chemistry

\section{Introduction}

Nanotechnology has been applied to a wide range of foods in the food industry to improve the stability, shelf-life, process convenience, quality, and nutritional values of processed foods [1-3]. Nanomaterials can be manufactured by two different methods, top-down and bottom-up approaches, and added as food additives, ingredients, and raw materials [4,5]. In the European Commission (EC), nanomaterials are defined as materials consisting of more than $50 \%$ of constituent particles in the size range of 1 to $100 \mathrm{~nm}$ based on number size distribution, including agglomerates or aggregates whenever the constituent particles belong to 1-100 nm [6]. Until now, most countries did not regulate the usage and labeling of nanomaterials in food products [7-9]. However, nanoparticles (NPs) have different properties compared with those of conventional bulk-sized particles (BPs), such as large surface area to volume ratios and high reactivity $[10,11]$, which can affect their biological responses and toxicity [12,13]. Moreover, NPs are added in complex food matrices, leading to interactions between NPs and food components, which can also cause changes in the physicochemical properties of NPs $[2,14,15]$. Indeed, NPs can be decomposed into small molecules/ionic forms or form large aggregates with other molecules present in foods or biological systems, and thus NPs may not be further present in commercial products and in the body $[2,16]$. In this case, the toxicity evaluation of NPs can be followed according to relevant guidance for conventional materials [16]. The determination of the presence 
and fate of NPs in commercial processed foods is of importance to understand and predict their potential toxicity.

Many studies have focused on the characterization and toxicity evaluation of engineered inorganic NPs produced by bottom-up approaches. Indeed, the identification and fate determination of food additive silicon dioxide and titanium dioxide NPs in commercial food products were reported; silicon dioxide particles were found to be nano-sized aggregated particles of less than $100 \mathrm{~m}$, whereas most titanium dioxide particles were determined to be larger than $100 \mathrm{~nm}$ [17-20]. Meanwhile, top-down approaches such as milling, grinding, homogenization, microfluidization, and high-speed rotary strike crushing are more generally applied to foods [21,22]. They are easy and effective methods to obtain nano-sized particles. However, the components of many functional and nutritional processed foods containing a variety of matrices cannot be exactly defined. Moreover, the most important nutritional components of foods are soft organic materials such as carbohydrates, proteins, lipids, vitamins, etc., which are incompatible with the conditions of electron microscopy, which is essential for size determination [16,22]. Hence, it is challenging to determine and characterize top-down-approach-produced (TD)-NPs in complex food products [16].

A wide range of commercial foods manufactured by top-down approaches are currently available on the market and labeled as nanoproducts [3,23]. Complex nano-powder products obtained by milling or grinding techniques of well-known conventional nutritional foods belong to this category [21]. Indeed, nanoproducts made from red ginseng, mushroom, soybean, ginko, grape seed, and lactic acid bacteria are on the market. These TD-NP products are aimed at increasing the oral absorption, bioavailability, and functional efficacy of active compounds related to nanosize [3,24,25]. On the other hand, waters containing nanobubbles have also attracted much attention. Nanobubble waters (NBWs) are produced by mixing gas (air, $\mathrm{N}_{2}, \mathrm{H}_{2}, \mathrm{O}_{2}$, and $\mathrm{CO}_{2}$ ) with water through different kinds of nanobubble generators, consequently having stable nanoscale bubbles suspended in the water [26]. NBWs have been reported to possess the potential to increase the seed germination rate [27-29], to promote the growth of plants [27,29], shellfish [30,31], and microorganism activity via fermentation [26], and to inhibit tumor cell development [32,33]. The functionality of NBWs was reported to be associated with the stability of nanobubbles in water, negative zeta potentials, and the generation of free radicals $[26,30]$. The mechanism of action of NBWs for seed and plant growing is still under investigation, but could be explained by the roles of stable nanobubbles $\left(\mathrm{N}_{2}\right.$ and $\left.\mathrm{O}_{2}\right)$ in nutrient elements, thereby increasing metabolic activities [27,29].

The aim of this study was to characterize and determine the presence of NPs in nano-labeled processed foods. Commercially available processed foods with different manufactured forms, TD-NPs and NBWs, were chosen as representative powdered and liquid nanoproducts, respectively. The constituent particle sizes, size distributions, hydrodynamic diameters, surface chemistry, and the presence of NPs in commercial products were determined by applying and optimizing electron microscopy, dynamic electron microscopy (DLS), and X-ray photoelectron spectroscopy (XPS).

\section{Materials and Methods}

\subsection{Materials}

Seven commercial NBWs were purchased from different international manufacturers on the online market and numbered as NBW-1 to NBW-7 (Table S1). For comparative study, two different conventional sparkling waters (SWs) were supplied by a local company and numbered as SW-1 and SW-2. Seven powdered TD-NP foods indicated on product labeling were also obtained from different international manufacturers on the online market and numbered as NP-1 to NP-7 (Table S1). Two different conventional bulk-sized powdered foods manufactured by local companies were also purchased for comparative study and numbered as BP-1 (equivalent component to NP-1) and BP-2 (equivalent component to 
NP-2). The major components of NBWs and TD-NPs are listed in Table S1. All commercial foods were stored at $4{ }^{\circ} \mathrm{C}$ before analysis.

\subsection{Sample Preparation}

For powdered foods, a suspension $(1 \mathrm{mg} / \mathrm{mL})$ of each product was prepared by stirring in distilled water (DW) for $30 \mathrm{~min}$, followed by sonication (160 Watts, Bransonic 5800 , Branson Ultrasonics, Danbury, CT, USA) at $25^{\circ} \mathrm{C}$ for $30 \mathrm{~min}$ (except inorganic-based NP-7 for $5 \mathrm{~min}$ ) prior to experiments.

\subsection{Dynamic Light Scattering and Electrophoretic Light Scattering Analysis}

Hydrodynamic diameters and zeta potentials of nanobubbles in NBWs and NPs in powdered TD-NP foods were evaluated by DLS and electrophoretic light scattering (ELS), respectively, using a Zetasizer Nano System (Malvern Instruments, Worcestershire, UK). The hydrodynamic diameters of nanobubbles in NBWs were immediately measured after opening at 2 or $25{ }^{\circ} \mathrm{C}$, and ELS analysis for all samples was performed at $25{ }^{\circ} \mathrm{C}$. The stability of nanobubbles in NBWs was investigated by performing DLS and ELS analysis after storage at $4{ }^{\circ} \mathrm{C}$ for 6 months.

\subsection{Scanning Electron Microscopic Analysis}

The constituent particle sizes and shapes of powdered TD-NPs or their counterpart conventional BPs were determined by scanning electron microscopy (SEM; JSM-7800F Prime, JEOL, Tokyo, Japan). To observe TD-NP or conventional BP products as they are without any dispersion procedure, the powdered samples were directly placed onto a mount (SPECIMEN MOUNT, JEOL, Tokyo, Japan) with carbon tape (5 $\mathrm{mm} \times 5 \mathrm{~mm}$; ESONG EMC, Seoul, Korea), and the excess powders were blown off with an air gun. On the other hand, $20 \mu \mathrm{L}$ of the suspended samples after dispersion (stirring and sonication), as described in "2.1. Materials", was dropped on the aluminum foil and dried at room temperature for $24 \mathrm{~h}$. The aluminum foil loaded with the sample was attached to a mount with the carbon tape $(5 \mathrm{~mm} \times 5 \mathrm{~mm})$. For all samples, the sample surface was coated with $\mathrm{Pt} / \mathrm{Pd}$ via a sputtering process for $70 \mathrm{~s}$. SEM images were obtained at $5-10 \mathrm{kV}$ of low acceleration voltage [34-36]. The average particle sizes and size distributions were measured by randomly selecting more than 100 discrete particles from the SEM using ImageJ software (version 1.53a, National Institutes of Health, Bethesda, MD, USA).

\subsection{Cryogenic Transmission Electron Microscopic Analysis}

The constituent particle sizes and shapes of powdered TD-NPs or conventional BPs were determined by cryogenic transmission electron microscopy (cryo-TEM; Tecnai G2 Spirit TWIN, FEI, Hillsboro, OR, USA). The specimens for cryo-TEM analysis were prepared using an automated vitrification system $\left(\right.$ Vitrobot $^{\circledR} ;$ FEI, Eindhoven, The Netherlands) at $26^{\circ} \mathrm{C}$ with a relative humidity of $100 \%$. A droplet $(3 \mu \mathrm{L})$ of the suspension as prepared in "Materials" was deposited on a lacey carbon film on a copper TEM grid and excess water was removed from the suspended sample by blotting with filter papers. Then, the grid was rapidly immersed in liquid ethane and transferred into liquid nitrogen. The vitrified specimens were observed at an accelerating voltage of $120 \mathrm{kV}$. The average particle sizes and size distributions were measured by randomly selecting more than 100 discrete particles from the cryo-TEM images using ImageJ software (version 1.53a, National Institutes of Health, Bethesda, MD, USA).

\subsection{Surface Chemical Analysis}

The surface chemical analysis for powdered TD-NPs or conventional BPs was performed by XPS (K-Alpha XPS, Thermo Fisher Scientific, West Palm Beach, FL, USA) using Al-K $\alpha$ X-ray source with a nominal spot size of $200 \mu \mathrm{m}$. The powdered samples were fixed on a sample holder using conductive carbon tape. Survey spectra were obtained at $200 \mathrm{eV}$ pass energy and $1.0 \mathrm{eV}$ energy step of the analyzer and recorded from 1350 to $0 \mathrm{eV}$. 
The individual high-resolution spectra for $\mathrm{C} 1 \mathrm{~s}, \mathrm{O} 1 \mathrm{~s}$, and $\mathrm{N} 1 \mathrm{~s}$ were recorded at $40 \mathrm{eV}$ pass energy and $0.05 \mathrm{eV}$ energy step. The obtained high-resolution spectra were fitted using Igor Pro software (version 8.04, Wavemetrics, Lake Oswego, OR, USA).

\subsection{Statistical Analysis}

Results were presented as means \pm standard deviations. A one-way analysis of variance (ANOVA) with Tukey's test was performed using SAS version 9.4 (SAS Institute Inc., Cary, NC, USA) to determine the significances of intergroup differences. Statistical significance was accepted for $p$ values of less than 0.05 .

\section{Results}

\subsection{Characterization of Nanobubbles in NBWs}

The presence of nano-sized bubbles in NBWs and their size distributions were determined by measuring the hydrodynamic diameters. Table 1 shows that polydispersity index (PDI) values for all products, except NBW-2, were higher than 0.9 , and unstable DLS histograms were observed when DLS analysis of NBWs and SWs was performed at $25^{\circ} \mathrm{C}$. Thus, the analysis was further carried out at $2{ }^{\circ} \mathrm{C}$ because bubbles are generally stable at refrigeration temperature. The results show that NBW-2 and NBW-4 had 100\% of particle fractions larger than $200 \mathrm{~nm}$, and a portion of particle fractions ranging from 100 to $200 \mathrm{~nm}$ were present in NBW-1, NBW-5, and NBW-7 (Table 2).

Table 1. Particle fractions and hydrodynamic diameters of bubbles in NBWs or in conventional SWs at $25^{\circ} \mathrm{C}^{1}$.

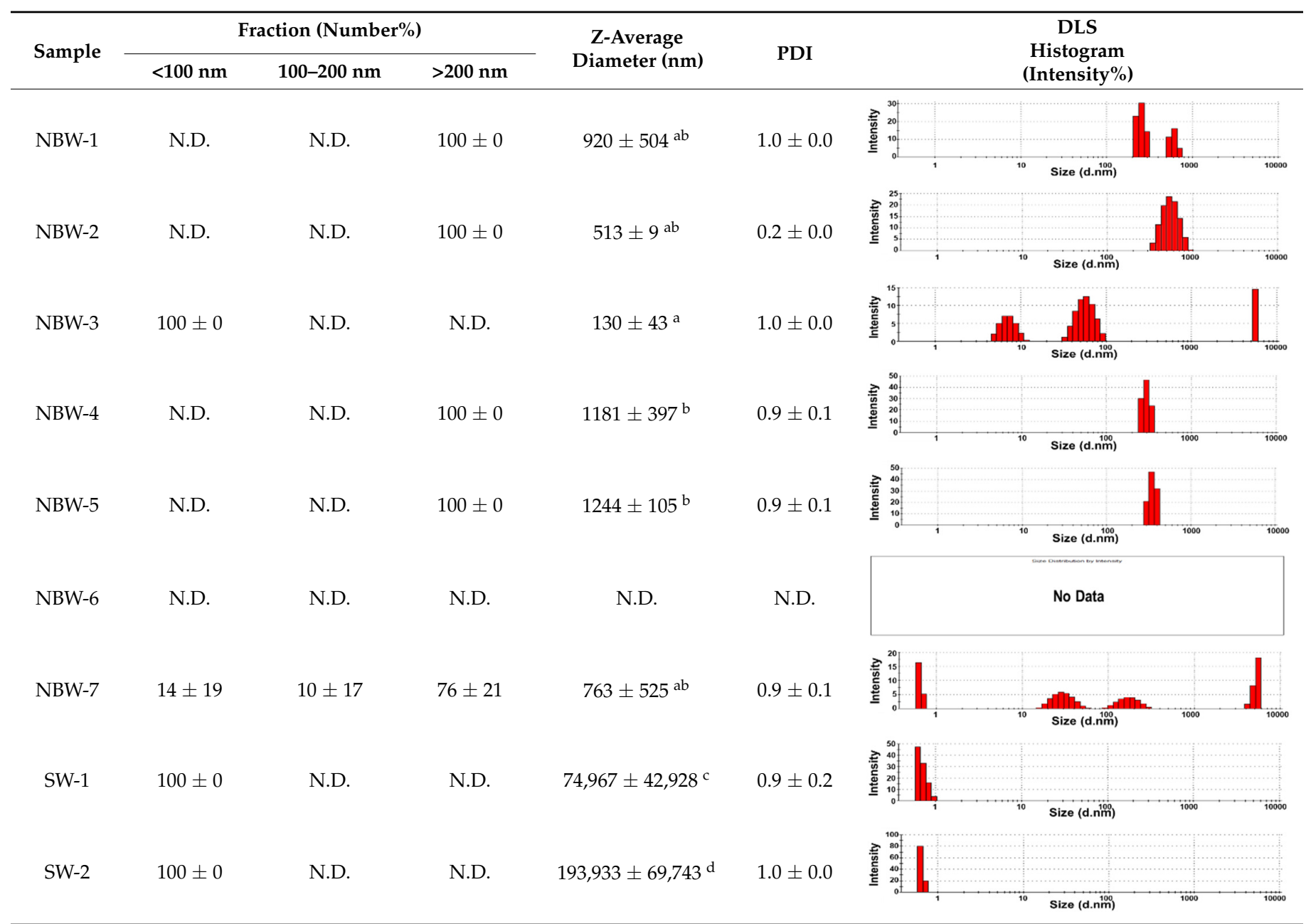

$1, a, b, c$, and ${ }^{d}$ indicate significant differences among NBWs and conventional SWs $(p<0.05)$. NBWs, nanobubble waters; SWs, sparkling waters; PDI, polydispersity index; DLS, dynamic light scattering; N.D., not detectable. 
Table 2. Particle fractions, hydrodynamic diameters, and surface charges of bubbles in NBWs or in conventional SWs ${ }^{1}$.

\begin{tabular}{|c|c|c|c|c|c|c|c|}
\hline \multirow{2}{*}{ Sample } & \multicolumn{3}{|c|}{ Fraction (Number\%) } & \multirow{2}{*}{$\begin{array}{c}\text { Z-Average } \\
\text { Diameter (nm) }\end{array}$} & \multirow{2}{*}{ PDI } & \multirow{2}{*}{$\begin{array}{c}\text { DLS } \\
\text { Histogram } \\
\text { (Intensity\%) }\end{array}$} & \multirow{2}{*}{$\begin{array}{c}\text { Zeta } \\
\text { Potential } \\
(\mathrm{mV})\end{array}$} \\
\hline & $<100 \mathrm{~nm}$ & $100-200 \mathrm{~nm}$ & $>200 \mathrm{~nm}$ & & & & \\
\hline NBW-1 & N.D. & $39 \pm 31$ & $61 \pm 31$ & $422 \pm 29^{c}$ & $0.5 \pm 0.2$ & & $-20 \pm 2^{a}$ \\
\hline NBW-2 & N.D. & N.D. & $100 \pm 0$ & $454 \pm 33^{c}$ & $0.2 \pm 0.0$ & & $-8 \pm 0^{\mathrm{cd}}$ \\
\hline NBW-3 & $100 \pm 0$ & N.D. & N.D. & $132 \pm 53^{a}$ & $0.9 \pm 0.1$ & & $-10 \pm 2^{c}$ \\
\hline NBW-4 & N.D. & N.D. & $100 \pm 0$ & $732 \pm 51^{d}$ & $0.2 \pm 0.1$ & & $-6 \pm 2^{c d}$ \\
\hline NBW-5 & N.D. & $13 \pm 14$ & $87 \pm 14$ & $386 \pm 39^{c}$ & $0.3 \pm 0.1$ & & $-8 \pm 2^{\mathrm{cd}}$ \\
\hline NBW-6 & $100 \pm 0$ & N.D. & N.D. & $18 \pm 6^{b}$ & $1.0 \pm 0.0$ & ${ }^{10}$ Size (d. dinm) & $-5 \pm 1^{d}$ \\
\hline NBW-7 & N.D. & $5 \pm 5$ & $95 \pm 5$ & $369 \pm 30^{c}$ & $0.4 \pm 0.2$ & & $-15 \pm 2^{b}$ \\
\hline SW-1 & $100 \pm 0$ & N.D. & N.D. & $35,820 \pm 7653^{e}$ & $1.0 \pm 0.0$ & "isize (d. inm) & $-0 \pm 0^{\mathrm{e}}$ \\
\hline SW-2 & $100 \pm 0$ & N.D. & N.D. & $61,587 \pm 33,772 \mathrm{e}$ & $1.0 \pm 0.0$ & ${ }^{10}$ Size (d. dinm) & $-0 \pm 1^{\mathrm{e}}$ \\
\hline DW & $100 \pm 0$ & N.D. & N.D. & $219 \pm 10^{a}$ & $1.0 \pm 0.0$ & ${ }^{10}$ Size (d.ñm) & N.D. \\
\hline
\end{tabular}

$1, \mathrm{a}, \mathrm{b}, \mathrm{c}, \mathrm{d}$ and ${ }^{\mathrm{e}}$ indicate significant differences among NBWs and conventional SWs $(p<0.05)$. Dynamic light scattering and electrophoretic light scattering measurements were performed at 2 and $25^{\circ} \mathrm{C}$, respectively. NBWs, nanobubble waters; SWs, sparkling waters; PDI, polydispersity index; DLS, dynamic light scattering; N.D., not detectable; DW, distilled water.

The Z-average diameters of nanobubbles in all NBWs were larger than $300 \mathrm{~nm}$, considering that the PDI values ranged from 0.2 to 0.5 . In the case of NBW-3 and NBW-6, the PDI values were 0.9 and 1.0, respectively, as high as observed in DW, and DLS histograms were not stable. Conventional SWs showed unstable DLS histograms and PDI values of 1 . The Z-average diameters of SW- 1 and SW-2 were determined to be more than $30,000 \mathrm{~nm}$. On the other hand, the ELS results indicate that the zeta potentials of all NBWs were negative and ranged from -20 to $-5 \mathrm{mV}$, whereas zeta potentials of SW-1 and SW-2 were close to $0 \mathrm{mV}$.

The stability of NBWs was checked after storage at refrigeration temperature for 6 months by performing DLS analysis. Table 3 demonstrates that the Z-average diameters and PDI values increased compared with those in Table 2, and unstable DLS histograms were observed for all products, except NBW-2 and NBW-5. The zeta potential values for all NBWs were negative after storage for 6 months but changed to less negative charges compared with those in Table 2, except NBW-2 and NBW-5. 
Table 3. Particle fractions, hydrodynamic diameters, and surface charges of nanobubbles in NBWs after storage for 6 months ${ }^{1}$.

\begin{tabular}{|c|c|c|c|c|c|c|c|}
\hline \multirow{2}{*}{ Sample } & \multicolumn{3}{|c|}{ Fraction (Number\%) } & \multirow{2}{*}{$\begin{array}{c}\text { Z-Average } \\
\text { Diameter (nm) }\end{array}$} & \multirow{2}{*}{ PDI } & \multirow{2}{*}{$\begin{array}{c}\text { DLS } \\
\text { Histogram } \\
\text { (Intensity\%) }\end{array}$} & \multirow{2}{*}{$\begin{array}{c}\text { Zeta } \\
\text { Potential } \\
(\mathrm{mV})\end{array}$} \\
\hline & $<100 \mathrm{~nm}$ & $100-200 \mathrm{~nm}$ & $>200 \mathrm{~nm}$ & & & & \\
\hline NBW-1 & N.D. & $4 \pm 6$ & $96 \pm 6$ & $601 \pm 85^{d}$ & $0.7 \pm 0.1$ & & $-8 \pm 1^{\mathrm{c}}$ \\
\hline NBW-2 & N.D. & N.D. & $100 \pm 0$ & $402 \pm 14^{c}$ & $0.2 \pm 0.0$ & & $-8 \pm 2^{c}$ \\
\hline NBW-3 & $100 \pm 0$ & N.D. & N.D. & $193 \pm 92^{b}$ & $0.9 \pm 0.1$ & & $-1 \pm 1^{\mathrm{a}}$ \\
\hline NBW-4 & N.D. & N.D. & $100 \pm 0$ & $907 \pm 238^{d}$ & $0.9 \pm 0.1$ & & $-3 \pm 1^{b}$ \\
\hline NBW-5 & N.D. & $6 \pm 6$ & $94 \pm 5$ & $358 \pm 103^{c}$ & $0.3 \pm 0.1$ & & $-7 \pm 1^{c}$ \\
\hline NBW-6 & $100 \pm 0$ & N.D. & N.D. & $19 \pm 5^{a}$ & $1.0 \pm 0.1$ & ${ }^{10}$ Size (d., dim) & $-1 \pm 0^{\mathrm{a}}$ \\
\hline NBW-7 & $8 \pm 14$ & $46 \pm 45$ & $46 \pm 48$ & $414 \pm 115^{\mathrm{cd}}$ & $0.9 \pm 0.2$ & & $-6 \pm 2^{b c}$ \\
\hline
\end{tabular}

$1, a, b, c, a^{d}{ }^{d}$ indicate significant differences among NBWs $(p<0.05)$. Dynamic light scattering and electrophoretic light scattering measurements were performed at 2 and $25^{\circ} \mathrm{C}$, respectively. NBWs, nanobubble waters; PDI, polydispersity index; DLS, dynamic light scattering; N.D., not detectable.

\subsection{Characterization of Powdered TD-NP Foods}

The size distributions and morphology of TD-NPs were determined by SEM with/without dispersion. Comparative study with conventional BP-1 and BP-2 composed of equivalent components to NP-1 and NP-2, respectively, but conventionally produced, was also performed. Counterpart conventional BPs were not available on the market for other TD-NPs. The SEM analysis was carried out at a low voltage of 5-10 kV because most commercially available TD-NP products contain many organic matrices, except NP-7, and these organic matrices are sensitive to irradiation by electrons [34-36]. Figure 1 demonstrates that TDNPs were highly aggregated without any dispersion. More dispersed but still aggregated particles were observed after stirring and sonication in all cases. The average particle sizes of all TD-NPs were less than $100 \mathrm{~nm}$ except NP-3, as determined by randomly selecting at least 100 particles from the SEM images. The relatively small constituent particle size of NP-7 consisting of an inorganic matrix was found.

On the other hand, large constituent particle sizes of conventional BP-1 and BP-2 compared with those of NP-1 and NP-2 were examined even after stirring and sonication, showing average sizes of about 516 and $1138 \mathrm{~nm}$ for BP-1 and BP-2, respectively.

The DLS results reveal that the Z-average diameters of TD-NPs dispersed in DW ranged from 327 to $2148 \mathrm{~nm}$, indicating their aggregate states under aqueous conditions (Table 4). The particle fractions of all TD-NPs were larger than $200 \mathrm{~nm}$, except NP-6 (93\% of particle fraction less than $100 \mathrm{~nm}$ ). Meanwhile, the Z-average diameters of conventional BPs were also larger than $1000 \mathrm{~nm}$, with 100\% of particle fractions larger than $200 \mathrm{~nm}$. The ELS results demonstrate that the zeta potential values for all powdered nano and bulk products were negative. 


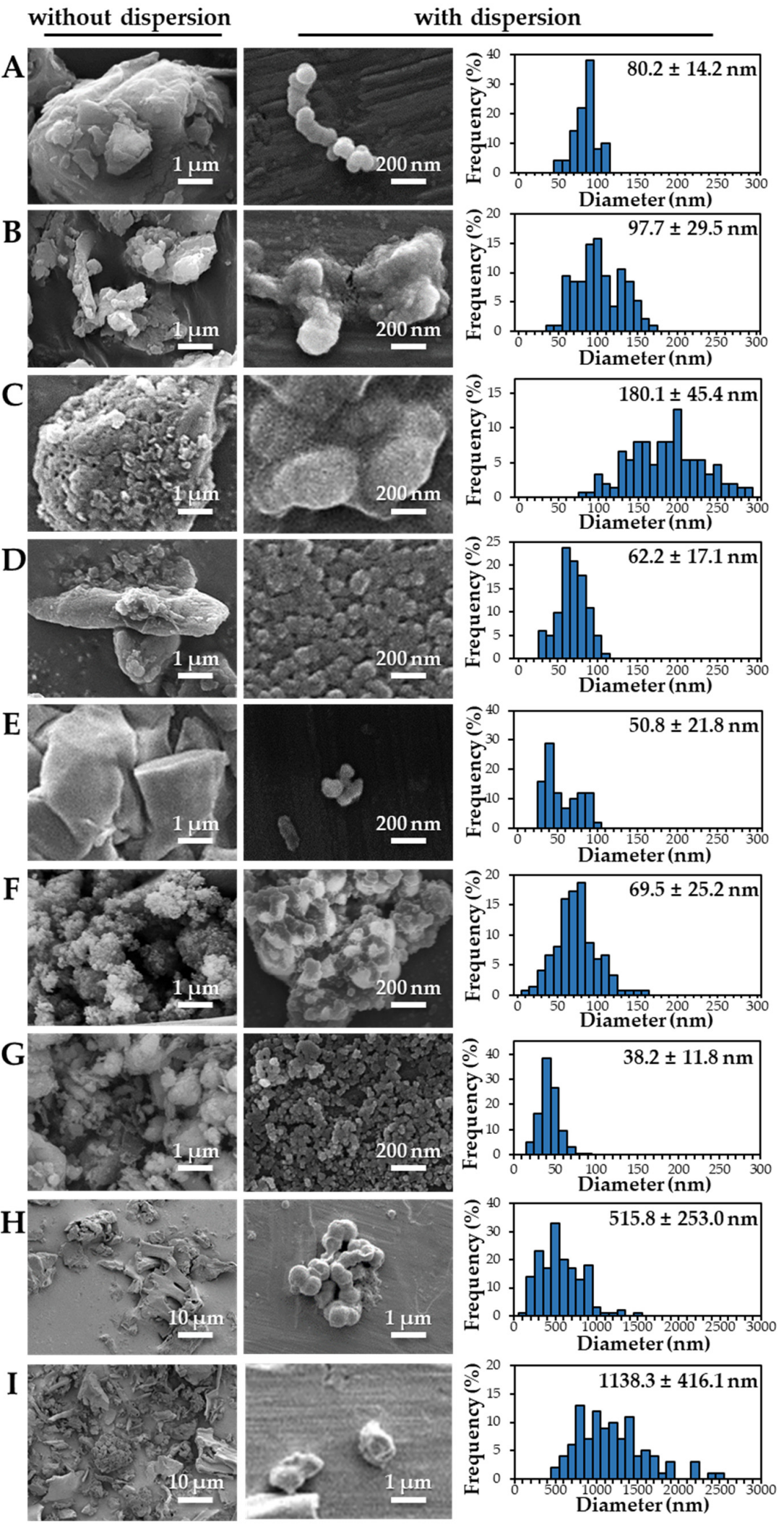

Figure 1. Scanning electron microscopy (SEM) images and size distributions of TD-NPs or conventional bulk-sized BP-1 and BP-2 composed of the same components as NP-1 and NP-2, respectively. (A) NP-1, (B) NP-2, (C) NP-3, (D) NP-4, (E) NP-5, (F) NP-6, (G) NP-7, (H) BP-1, and (I) BP-2. The size distributions of constituent particles were determined by randomly selecting more than 100 particles from the SEM images. Abbreviations: TD-NP, top-down-approach-produced nanoparticle; BP, bulk-sized particle; NP, nanoparticle. 
Table 4. Particle fractions, hydrodynamic diameters, and surface charges of TD-NPs and conventional BPs at $25^{\circ} \mathrm{C}^{1}$.

\begin{tabular}{|c|c|c|c|c|c|c|}
\hline \multirow{2}{*}{ Sample } & \multicolumn{3}{|c|}{ Fraction (Number\%) } & \multirow{2}{*}{$\begin{array}{c}\text { Z-Average } \\
\text { Diameter (nm) }\end{array}$} & \multirow{2}{*}{ PDI } & \multirow{2}{*}{$\begin{array}{c}\text { Zeta } \\
\text { Potential }(\mathrm{mV})\end{array}$} \\
\hline & $<100 \mathrm{~nm}$ & $100-200 \mathrm{~nm}$ & $>200 \mathrm{~nm}$ & & & \\
\hline NP-1 & N.D. & N.D. & $100 \pm 0$ & $1771 \pm 17^{\mathrm{cd}}$ & $0.7 \pm 0.3$ & $-21 \pm 1^{\mathrm{d}}$ \\
\hline NP-2 & N.D. & N.D. & $100 \pm 0$ & $800 \pm 30^{b}$ & $0.2 \pm 0.1$ & $-35 \pm 0^{b}$ \\
\hline NP-3 & N.D. & N.D. & $100 \pm 0$ & $1756 \pm 304^{\mathrm{cd}}$ & $0.7 \pm 0.1$ & $-27 \pm 1^{c}$ \\
\hline NP-4 & N.D. & N.D. & $100 \pm 0$ & $1198 \pm 65^{c}$ & $0.2 \pm 0.0$ & $-31 \pm 1^{b c}$ \\
\hline NP-5 & N.D. & N.D. & $100 \pm 0$ & $1403 \pm 232^{c}$ & $0.2 \pm 0.1$ & $-32 \pm 1^{b}$ \\
\hline NP-6 & $93 \pm 11$ & $6 \pm 11$ & $1 \pm 0$ & $327 \pm 8^{a}$ & $0.5 \pm 0.1$ & $-20 \pm 0^{\mathrm{d}}$ \\
\hline NP-7 & N.D. & N.D. & $100 \pm 0$ & $2148 \pm 376^{d}$ & $0.3 \pm 0.3$ & $-14 \pm 3^{\mathrm{e}}$ \\
\hline BP-1 & N.D. & N.D. & $100 \pm 0$ & $1246 \pm 126^{c}$ & $0.3 \pm 0.2$ & $-27 \pm 3^{c}$ \\
\hline BP-2 & N.D. & N.D. & $100 \pm 0$ & $1788 \pm 53^{\mathrm{cd}}$ & $0.2 \pm 0.0$ & $-47 \pm 2^{a}$ \\
\hline
\end{tabular}

$1, \mathrm{a}, \mathrm{b}, \mathrm{c}, \mathrm{d}$, and $^{\mathrm{e}}$ indicate significant differences among TD-NPs and conventional BPs $(p<0.05)$. TD-NPs, top-down-approach-produced nanoparticles; BPs, bulk-sized particles; PDI, polydispersity index; N.D., not detectable.

\subsection{Constituent Particle Sizes of Powdered TD-NP Foods}

The constituent particle sizes and shapes of TD-NPs consisting of organic matrices (NP-1 to NP-6) and conventional BPs were further examined by cryo-TEM after dispersion (stirring and sonication). Cryo-TEM is a powerful tool to determine the structure, size, and shape of soft organic materials incompatible with the conditions of electron microscopic measurements [34,37]. This is based on ultra-fast cooling and conversion of a liquid sample to a vitrified glassy specimen, which permits TEM analysis without significant morphological changes [37]. The results show that the average sizes of constituent particles of all TD-NPs were smaller than those observed by SEM (Figure 1), showing 20 to $40 \mathrm{~nm}$ (Figure 2). The particles were present as both individual separated particles and aggregated forms in all cases. Rounded or irregular particle shapes were observed depending on material types. On the other hand, conventional BP-1 and BP-2 had larger average sizes (larger than $100 \mathrm{~nm}$ ) and broader size distributions of constituent particles than those of NP-1 and NP-2, respectively.

\subsection{Surface Chemical Characterization of Powdered TD-NP Foods}

XPS analysis was performed to compare the elemental composition and chemical state of NP-1 and NP-2 with those of conventional BP-1 and BP-2. The spectra survey shows that peaks at 532, 399, and $284 \mathrm{eV}$ correspond to O1s, N1s, and C1s, respectively (Figure 3). Based on these spectra, the chemical compositions (\%) of three main elements $(\mathrm{O}, \mathrm{N}$, and $\mathrm{C})$ between NP-1 and BP-1 were highly similar, whereas slightly different elemental compositions between NP-2 and BP-2 were found. When spectra of each element were examined, O1s spectra of NP-1, NP-2, and BP-2 were deconvoluted into two peaks attributed to structural bonds of $\mathrm{O}=\mathrm{C}$ at $531.4 \mathrm{eV}$ and $\mathrm{O}-\mathrm{C}$ at $532.4 \mathrm{eV}$, whereas a peak of $\mathrm{O}-\mathrm{C}-\mathrm{O}$ at $533.4 \mathrm{eV}$, together with $\mathrm{O}=\mathrm{C}$ and $\mathrm{O}-\mathrm{C}$ bonds, was determined only in BP-1. Intensity changes in $\mathrm{O}=\mathrm{C}$ and $\mathrm{O}-\mathrm{C}$ between $\mathrm{NP}-1$ and $\mathrm{BP}-1$ were also remarkably found, which was not observed between NP-2 and BP-2. The peaks of N1s spectra for NP-1, $\mathrm{NP}-2, \mathrm{BP}-1$, and BP-2 correspond to the $\mathrm{NH}_{2}-\mathrm{C}$ bond at $399.3 \mathrm{eV}$, and a peak of $\mathrm{NH}^{+}-\mathrm{C}$ at $401.36 \mathrm{eV}$ was detected only in $\mathrm{BP}-1$. In the case of $\mathrm{C} 1 \mathrm{~s}$, the spectra for all samples were commonly deconvoluted into three peaks at $284.1,285.6$, and $287.4 \mathrm{eV}$, corresponding to $\mathrm{C}-\mathrm{C} / \mathrm{C}-\mathrm{H}, \mathrm{C}-\mathrm{O}$, and $\mathrm{C}=\mathrm{O}$ bonds, respectively. Meanwhile, a peak of $\mathrm{O}-\mathrm{C}-\mathrm{O}$ at $286.5 \mathrm{eV}$ was only identified in BP-1. Intensity increases in $\mathrm{C}-\mathrm{C} / \mathrm{C}-\mathrm{H}$ and decreases in $\mathrm{C}=\mathrm{O}$ bonds in BPs compared with NPs were also observed. 
A

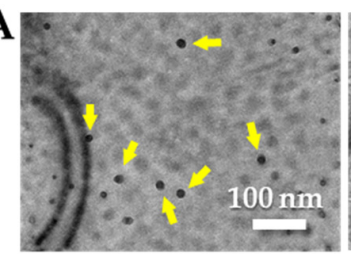

B

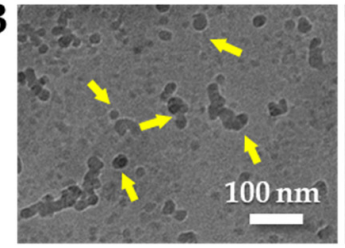

C

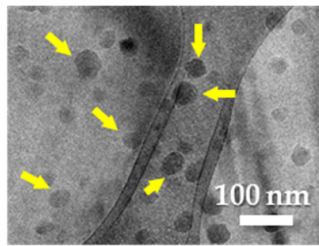

D

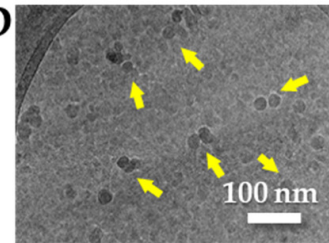

E

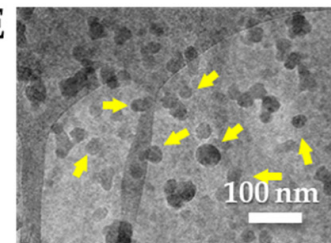

F

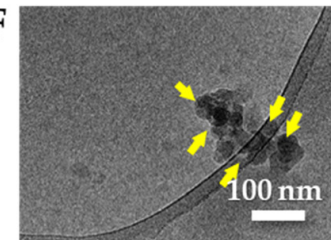

G
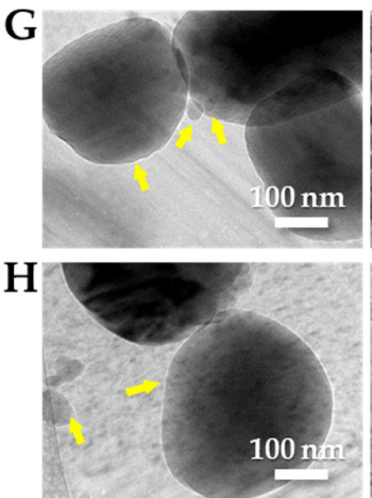
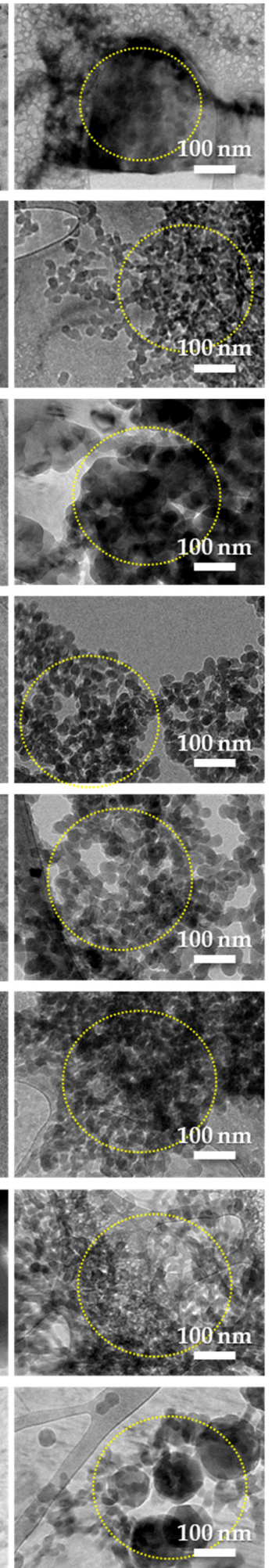
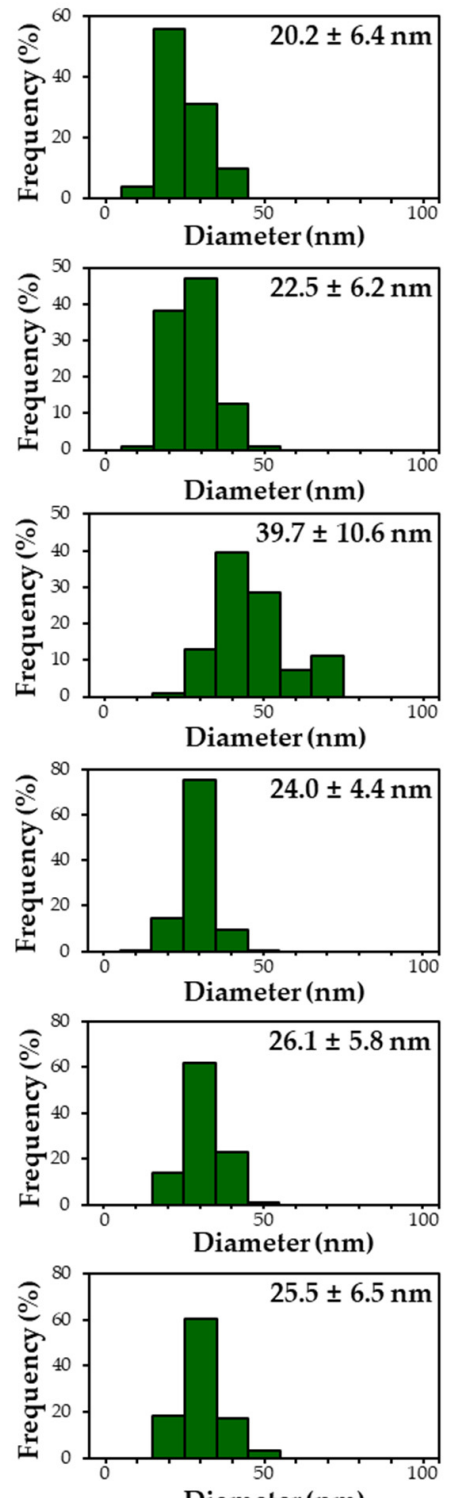

Diameter (nm)

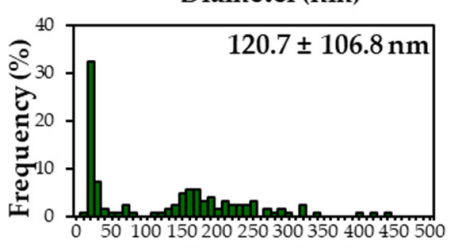

Diameter (nm)

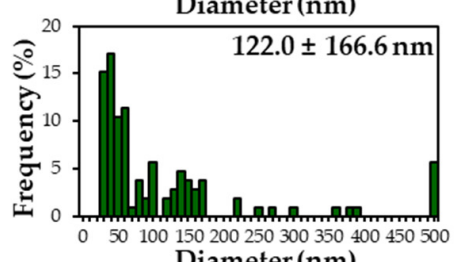

Figure 2. Cryogenic transmission electron microscopy (cryo-TEM) images and size distributions of TD-NPs or conventional BP-1 and BP-2 composed of the same components as NP-1 and NP-2, respectively. (A) NP-1, (B) NP-2, (C) NP-3, (D) NP-4, (E) NP-5, (F) NP-6, (G) BP-1, and (H) BP-2. Yellow arrows and yellow dotted lines indicate separated individual particles and aggregated forms, respectively. Particle size distributions were determined by randomly selecting more than 100 particles from the cryo-TEM images. Abbreviations: TD-NP, top-down-approach-produced nanoparticle; BP, bulk-sized particle; NP, nanoparticle. 

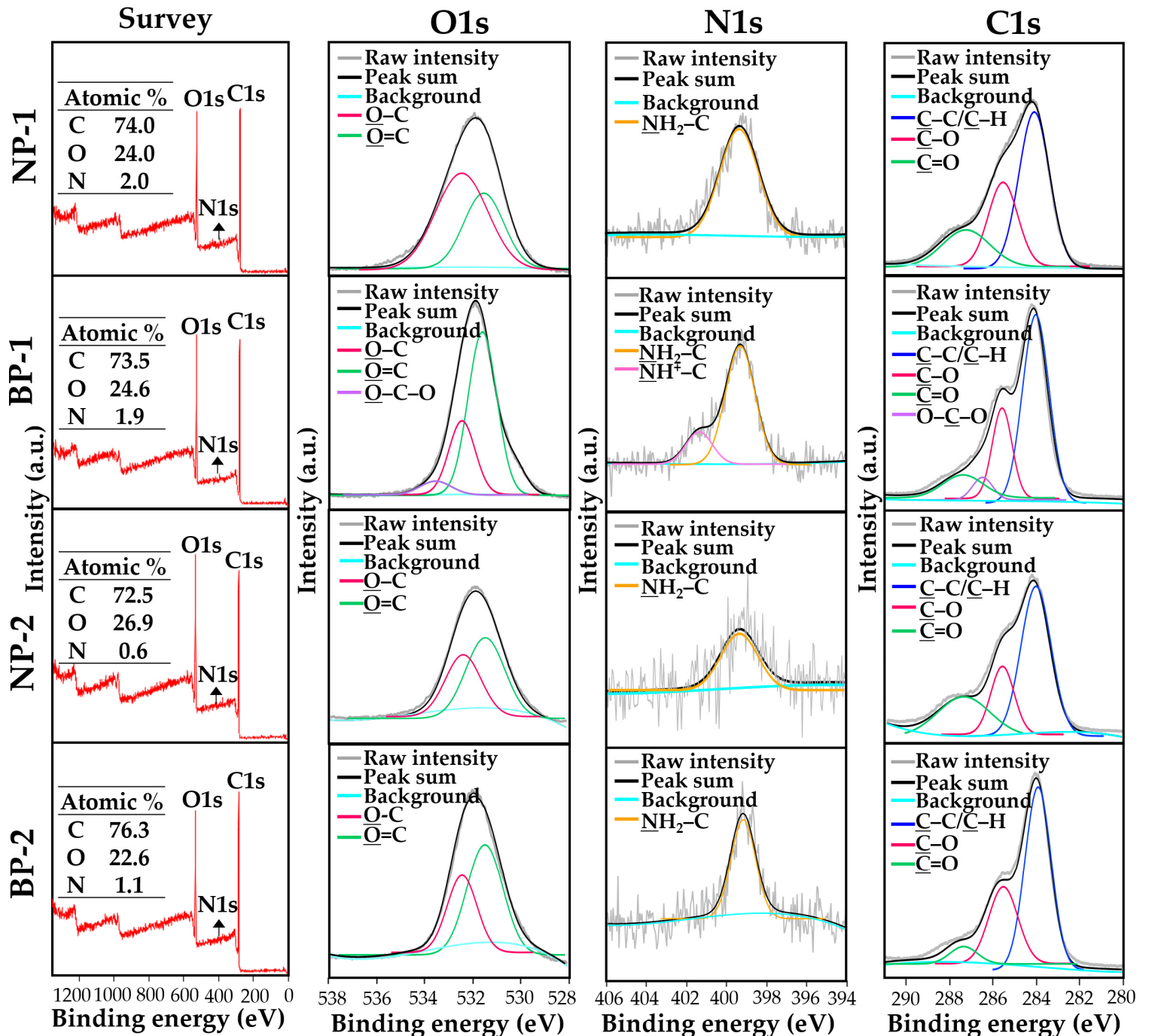

Figure 3. X-ray photoelectron spectroscopy (XPS) survey and high-resolution spectra (O1s, N1s, and C1s) of TD-NPs (NP-1 and NP-2) or conventional BPs (BP-1 and BP-2). Abbreviations: TD-NP, top-down-approach-produced nanoparticle; BP, bulk-sized particle; NP, nanoparticle.

\section{Discussion}

In this study, we characterized commercially available nano-labeled powdered and liquid foods, such as TD-NPs and NBWs, and the presence of NPs in processed foods was determined. The characterization of NPs in commercial products is of importance because diverse organic matrices in foods disturb the analysis of particle size using electron microscopy, and NPs have high reactivity compared with micro-sized materials. Moreover, the determination of NPs in commercial foods is crucial not only for the regulation of nano-labeled products, but also for the safety evaluation of NPs. If NPs are not present or completely decomposed in final products, nano-labeling is not allowed, and the toxicity evaluation of new nanomaterials is not mandatory or can be followed according to classical methods for conventional bulk-sized materials [16].

The DLS results show that the Z-average sizes measured at $2{ }^{\circ} \mathrm{C}$ were much smaller (Table 2) than those measured at $25^{\circ} \mathrm{C}$ (Table 1), when the sizes with reliable PDI values less than 0.7 were considered [38]. This can be explained by the high stability of gases at a low temperature [39,40]. The instability of bubbles was also clearly shown in the DLS histogram in Table 1 and in NBW-3 (Table 2). In all cases, no particle fractions less than $100 \mathrm{~nm}$ were observed and a small portion of fractions between 100 and $200 \mathrm{~nm}$ was found only in NBW-1, NBW-5, and NBW-7 (Table 2). It is worth noting that $100 \%$ of fractions less than 
$100 \mathrm{~nm}$ were detected in DW, but they cannot be considered as NPs due to the PDI value of 1.0 and unstable DLS histogram (Table 2). Hence, it seems that nanobubbles were not present in NBW-6, SW-1, and SW-2. The Z-average sizes and PDI values of all nanobubbles measured after 6 months increased, except NBW-2 and NBW-5 (Table 3), implying the instability of nanobubbles in NBWs during storage. The fact that the zeta potential values for all NBWs after 6 months, except NBW-2 and NBW-5, changed to less negative charges compared with those in Table 2 also supports the instability of nanobubbles in most NBWs (Table 3). All the results indicate that nanobubbles are not stable in most commercially available NBWs, and it is possible that nanobubbles less than $100 \mathrm{~nm}$ are not present at a commercially available stage. On the other hand, the Z-average diameters of bubbles in conventional SWs were much larger than those in NBWs under the same conditions, and the differences in zeta potentials between NBWs and SWs were clearly found (Table 2). These results suggest that NBWs have different physicochemical characteristics compared with those of conventional SWs, although no particles less than $100 \mathrm{~nm}$ were found in NBWs. Nevertheless, two among seven samples tested (NBW-2 and NBW-5) had stable PDI values, DLS histogram, zeta potential values, and Z-average diameters after 6 months. Hence, the manufacturing process applied to NBWs seems to differ from the conventional one. It is probable that nanobubbles are present at an initial stage just after production, but manufacturing technique, storage, and distribution conditions can be different from manufacturers, which affects the stability of nanobubbles. Further study to enhance the stability of nanobubbles in NBWs is required for nano-labeled products.

Our SEM results clearly show that the average sizes of powdered TD-NPs tested were less than $100 \mathrm{~nm}$, except NP-3, but they formed agglomerates or aggregates even after stirring and sonication (Figure 1). When the SEM images with/without dispersion are compared, it is clear that NP dispersion, such as stirring and sonication, is necessary to examine nano-sized particles in powdered TD-NP foods. Aggregate/agglomerate fates of TD-NPs were also confirmed by DLS results, except NP-6 (Table 4). Meanwhile, broader particle size distributions with larger average sizes ( 516 to $1138 \mathrm{~nm}$ ) of conventional BPs than those of TD-NPs were examined (Figure 1), indicating the difference in particle sizes between BPs and TD-NPs. It is worth noting that the SEM analysis was performed at a low acceleration voltage $(5-10 \mathrm{kV})$ due to high contents of organic matrices in all samples, except inorganic-based NP-7 [34-36].

More clear images on size distributions, constituent particle sizes, and shapes could be obtained by cryo-TEM analysis performed after vitrification, showing the presence of NPs less than $100 \mathrm{~nm}$, but aggregated fates in all organic-based powdered TD-NP foods (Figure 2). The average sizes of constituent particles ranged from $\sim 20$ to $40 \mathrm{~nm}$ (Figure 2), smaller than the sizes measured by SEM (Figure 1). The discrepancy in size between SEM and cryo-TEM analysis may be related to the preparation procedure for cryo-TEM specimens. Indeed, both SEM and cryo-TEM analysis were carried out after the stirring and sonication of the samples, but a further vitrification procedure was carried out for cryo-TEM specimens, and TEM analysis was performed under cryogenic conditions. Cryo-TEM involves an ultra-fast conversion of the state of the material from fluid to glassy without adding other compounds, thereby contributing to maintaining the intact composition or structure of the material [37]. These results indicate that stirring and sonication generally applied for electron microscopic analysis may not be enough to disperse TD-NPs agglomerated/aggregated with multi-components present in processed foods. Therefore, cryo-TEM analysis can be an effective approach to determine organicbased NPs in complex food systems. NP-3 had a larger constituent particle size than others by SEM (Figure 1) and cryo-TEM (Figure 2) analysis, implying the effect of matrix types or manufacturing process on the characteristics of TD-NPs. On the other hand, large average sizes $(\sim 120 \mathrm{~nm})$, broad size distributions up to $500 \mathrm{~nm}$, and high aggregates of conventional BPs compared with those of TD-NPs were found by cryo-TEM, supporting the presence of NPs in TD-NP products. Taken together, NPs were present in powdered TD-NP products by SEM and cryo-TEM analysis, although they formed high agglomerates 
or aggregates. It is worth noting that agglomerated or aggregated particles can exhibit the same property as unbound NPs when they are released from the agglomerates or aggregates under environmental and biological conditions, and thus they are included in the category of NPs [6]. Moreover, the number size distribution threshold of $50 \%$ in the size range 1-100 $\mathrm{nm}$ for NP definition may be replaced by a threshold between 1 and 50\% in specific cases where concerns for the environment, health, and safety are warranted $[6,16]$. Therefore, it can be concluded that the powdered TD-NP products tested contain nanosized agglomerated/aggregated particles. It is possible that TD-NPs have different toxicity compared with conventional BPs, and thus further study on biological responses of TD-NPs is required to be performed to ascertain their potential toxicity.

The XPS results demonstrate the differences in chemical state between NP-1 and BP-1 as well as in elemental composition between NP-2 and BP-2 (Figure 3). It is probable that top-down-based processing such as milling and grinding leads to the decomposition or formation of chemical bonds. In actual states, it is difficult to exactly explain the reason why such changes occur in TD-NP products, since they have various components including nutrients and functional ingredients. However, the remarkable changes in chemical bonds between NP-1 and BP-2 may be related to the poor stability of ginsenosides, the main functional components of ginsengs, against processing conditions, such as $\mathrm{pH}$, temperature, heat, and extract solvents [41]. The slightly different elemental compositions between NP-2 and BP-2 are more likely to be related to the compositions of raw materials or the degradation of certain compounds during TD-NP processing. These results suggest that elemental compositions and chemical bonds could be affected by top-down processing for NP products. The degree of chemical change may be associated with compositions of food matrices and processing methods. Surface chemical characterization using XPS can be a useful tool to differentiate NPs from conventional BPs. Further study on more extended samples is required to elucidate the mechanism involved in elemental and chemical changes. Moreover, the effect of food matrix types on the characteristics and safety aspects of NPs in commercial foods should also be elucidated.

\section{Conclusions}

In this study, the characterization of NPs in commercially available powdered and liquid foods was carried out and the presence of NPs was determined. The different characteristics between nanobubble waters and conventional sparkling waters were confirmed by Z-average diameters and zeta potential values. However, nanobubbles in most nanobubble waters tested were not stable during storage, and the presence of NPs less than $100 \mathrm{~nm}$ was not confirmed. On the other hand, constituent particles of less than $100 \mathrm{~nm}$ were clearly observed in powdered top-down-approach-produced NP products compared with those of conventional bulk-sized particles by SEM at a low acceleration voltage and cryo-TEM analysis, but they were present as agglomerated or aggregated forms. The differences in chemical composition and chemical state between top-down-approach-produced NPs and conventional bulk-sized particles were also found, suggesting a possible change in surface chemistry during top-down-approach processing. These findings will provide crucial information about the presence of NPs in nano-labeled products and be useful to understand and predict the potential toxicity of TD-NP foods. Further extended study on a wide range of nano-labeled foods is required to elucidate the mechanism involved in their characteristic changes. Moreover, the toxicity evaluation of nano-labeled products must be performed to ensure the safety of NPs in the food industry. 
Supplementary Materials: The following are available online at https: / www.mdpi.com/article/ 10.3390 / foods10092020/s1, Table S1: Major components of NBWs, conventional SWs, TD-NP, and conventional BP products.

Author Contributions: Validation, data curation, investigation, J.Y.; formal analysis, investigation, Y.-R.J.; investigation, Y.-H.K.; investigation, E.-B.J.; conceptualization, supervision, funding acquisition, resources, writing-original draft, S.-J.C. All authors have read and agreed to the published version of the manuscript.

Funding: This research was supported by a grant (20162MFDS051) from the Ministry of Food and Drug Safety in 2020, by the National Research Foundation of Korea (NRF) grant funded by the Korean government (MIST) (No. 2021R1A2C2007192), and partly by a research grant from Seoul Women's University (2021-0149).

Institutional Review Board Statement: Not applicable.

Informed Consent Statement: Not applicable.

Data Availability Statement: The data presented in this study are available in the article and Supplementary Materials.

Conflicts of Interest: The authors declare no conflict of interest.

\section{References}

1. He, X.; Deng, H.; Hwang, H.M. The current application of nanotechnology in food and agriculture. J. Food Drug Anal. 2019, 27, 1-21. [CrossRef]

2. McClements, D.J.; Xiao, H. Is nano safe in foods? Establishing the factors impacting the gastrointestinal fate and toxicity of organic and inorganic food-grade nanoparticles. NPJ Sci. Food 2017, 1, 6. [CrossRef]

3. Sekhon, B.S. Food nanotechnology-An overview. Nanotechnol. Sci. Appl. 2010, 3, 1-15.

4. Acosta, E. Bioavailability of nanoparticles in nutrient and nutraceutical delivery. Curr. Opin. Colloid Interface Sci. 2009, 14, 3-15. [CrossRef]

5. Oladipo, I.C.; Ishola, O.S. Appropriation of nanoparticle as food additive: A possibility. EJARBLS 2020, 8, 18-32.

6. European Commission. Commission recommendation of 18 October 2011 on the definition of nanomaterial (2011/696/EU). Off. J. Eur. Union 2011, L375, 38-40.

7. Akin, H.; Yeo, S.K.; Wirz, C.D.; Scheufele, D.A.; Brossard, D.; Xenos, M.A.; Corley, E.A. Are attitudes toward labeling nano products linked to attitudes toward GMO? Exploring a potential 'spillover' effect for attitudes toward controversial technologies. J. Responsible Innov. 2019, 6, 50-74. [CrossRef]

8. Amenta, V.; Aschberger, K.; Arena, M.; Bouwmeester, H.; Moniz, F.B.; Brandhoff, P.; Gottardo, S.; Marvin, H.J.P.; Mech, A.; Pesudo, L.Q.; et al. Regulatory aspects of nanotechnology in the agri/feed/food sector in EU and non-EU countries. Regul. Toxicol. Pharm. 2015, 73, 463-476. [CrossRef] [PubMed]

9. Chuah, A.S.F.; Leong, A.D.; Cummings, C.L.; Ho, S.S. Label it or ban it? Public perceptions of nano-food labels and propositions for banning nano-food applications. J. Nanopart. Res. 2018, 20, 36. [CrossRef]

10. Ameta, S.K.; Rai, A.K.; Hiran, D.; Ameta, R.; Ameta, S.C. Use of nanomaterials in food science. In Biogenic Nano-Particles and their Use in Agro-Ecosystems, 1st ed.; Ghorbanpour, M., Bhargava, P., Varma, A., Choudhary, D., Eds.; Springer: Singapore, 2020; pp. 457-488.

11. Rashidi, L.; Khosravi-Darani, K. The applications of nanotechnology in food industry. Crit. Rev. Food Sci. 2011, 51, 723-730. [CrossRef]

12. Aillon, K.L.; Xie, Y.; El-Gendy, N.; Berkland, C.J.; Forrest, M.L. Effects of nanomaterial physicochemical properties on in vivo toxicity. Adv. Drug Deliver. Rev. 2009, 61, 457-466. [CrossRef]

13. Yu, J.; Choi, S.J. Particle size and biological fate of $\mathrm{ZnO}$ do not cause acute toxicity, but affect toxicokinetics and gene expression profiles in the rat livers after oral administration. Int. J. Mol. Sci. 2021, 22, 1698. [CrossRef]

14. Go, M.R.; Bae, S.H.; Kim, H.J.; Yu, J.; Choi, S.J. Interactions between food additive silica nanoparticles and food matrices. Front. Microbiol. 2017, 8, 1013. [CrossRef]

15. Go, M.R.; Yu, J.; Bae, S.H.; Kim, H.J.; Choi, S.J. Effects of interactions between ZnO nanoparticles and saccharides on biological responses. Int. J. Mol. Sci. 2018, 19, 486. [CrossRef] [PubMed]

16. Hardy, A.; Benford, D.; Halldorsson, T.; Jeger, M.J.; Knutsen, H.K.; More, S.; Naegeli, H.; Noteborn, H.; Ockleford, C.; Ricci, A.; et al. Guidance on risk assessment of the application of nanoscience and nanotechnologies in the food and feed chain: Part 1, human and animal health. EFSA J. 2018, 16, e05327. [PubMed]

17. Athinarayanan, J.; Alshatwi, A.A.; Periasamy, V.S.; Al-Warthan, A.A. Identification of nanoscale ingredients in commercial food products and their induction of mitochondrially mediated cytotoxic effects on human mesenchymal stem cells. J. Food Sci. 2015, 80, N459-N464. [CrossRef] [PubMed] 
18. Chen, X.X.; Cheng, B.; Yang, Y.X.; Cao, A.; Liu, J.H.; Du, L.J.; Liu, Y.; Zhao, Y.; Wang, H. Characterization and preliminary toxicity assay of nano-titanium dioxide additive in sugar-coated chewing gum. Small 2013, 9, 1765-1774. [CrossRef]

19. Hwang, J.S.; Yu, J.; Kim, H.M.; Oh, J.M.; Choi, S.J. Food additive titanium dioxide and its fate in commercial foods. Nanomaterials 2019, 9, 1175. [CrossRef]

20. Yu, J.; Kim, Y.H.; Kim, H.M.; Oh, J.M.; Kim, Y.R.; Choi, S.J. Determination of the fate and biological responses of food additive silica particles in commercial foods. Food Chem. 2020, 331, 127304. [CrossRef]

21. Gao, W.; Chen, F.; Wang, X.; Meng, Q. Recent advances in processing food powders by using superfine grinding techniques: A review. Compr. Rev. Food Sci. Food Saf. 2020, 19, 2222-2255. [CrossRef]

22. Pan, K.; Zhong, Q. Organic nanoparticles in foods: Fabrication, characterization, and utilization. Annu. Rev. Food Sci. Technol. 2016, 7, 245-266. [CrossRef]

23. Sohal, I.S.; O'Fallon, K.S.; Gaines, P.; Demokritou, P.; Bello, D. Ingested engineered nanomaterials: State of science in nanotoxicity testing and future research needs. Part. Fibre Toxicol. 2018, 15, 29. [CrossRef]

24. Chaudhry, Q.; Watkins, R.; Castle, L. (Eds.) Nanotechnologies in food: What, why and how? In Nanotechnologies in Food, 2nd ed.; Royal Society of Chemistry: London, UK, 2017; pp. 1-19.

25. Erfanian, A.; Mirhosseini, H.; Rasti, B.; Hair-Bejo, M.; Mustafa, S.B.; Manap, M.Y.A. Absorption and bioavailability of nano-size reduced calcium citrate fortified milk powder in ovariectomized and ovariectomized-osteoporosis rats. J. Agric. Food Chem. 2015, 63, 5795-5804. [CrossRef]

26. Guo, Z.; Wang, X.; Wang, H.; Hu, B.; Lei, Z.; Kobayashi, M.; Adachi, Y.; Shimizu, K.; Zhang, Z. Effects of nanobubble water on the growth of Lactobacillus acidophilus 1028 and its lactic acid production. RSC Adv. 2019, 9, 30760-30767. [CrossRef]

27. Ahmed, A.K.A.; Shi, X.; Hua, L.; Manzueta, L.; Qing, W.; Marhaba, T.; Zhang, W. Influences of air, oxygen, nitrogen, and carbon dioxide nanobubbles on seed germination and plant growth. J. Agric. Food Chem. 2018, 66, 5117-5124. [CrossRef]

28. Liu, S.; Oshita, S.; Makino, Y.; Wang, Q.; Kawagoe, Y.; Uchida, T. Oxidative capacity of nanobubbles and its effect on seed germination. ACS Sustain. Chem. Eng. 2016, 4, 1347-1353. [CrossRef]

29. Rameshkumar, C.; Sankar, S.L.; Senthilkumar, G. Characterisation of seed germination using nanaobubbled water. Int. J. Ambient Energy 2019, 1-4. [CrossRef]

30. Ebina, K.; Shi, K.; Hirao, M.; Hashimoto, J.; Kawato, Y.; Kaneshiro, S.; Morimoto, T.; Koizumi, K.; Yoshikawa, H. Oxygen and air nanobubble water solution promote the growth of plants, fishes, and mice. PLoS ONE 2013, 8, e65339. [CrossRef]

31. Rafeeq, S.; Shiroodi, S.; Schwarz, M.H.; Nitin, N.; Ovissipour, R. Inactivation of Aeromonas hydrophila and Vibrio parahaemolyticus by curcumin-mediated photosensitization and nanobubble-ultrasonication approaches. Foods 2020, 9, 1306. [CrossRef] [PubMed]

32. Asada, R.; Kageyama, K.; Tanaka, H.; Matsui, H.; Kimura, M.; Saitoh, Y.; Miwa, N. Antitumor effects of nano-bubble hydrogendissolved water are enhanced by coexistent platinum colloid and the combined hyperthermia with apoptosis-like cell death. Oncol. Rep. 2010, 24, 1463-1470.

33. Perera, R.H.; Solorio, L.; Wu, H.; Gangolli, M.; Silverman, E.; Hernandez, C.; Peiris, P.M.; Broome, A.M.; Exner, A.A. Nanobubble ultrasound contrast agents for enhanced delivery of thermal sensitizer to tumors undergoing radiofrequency ablation. Pharm. Res. 2014, 31, 1407-1417. [CrossRef]

34. Mech, A.; Rauscher, H.; Babik, F.; Hodoroaba, V.D.; Ghanem, A.; Wohlleben, W.; Marvin, H.; Weigel, S.; Brungel, R.; Friedrich, C.M. The NanoDefine Methods Manual. Part 1: The NanoDefiner Framework and Tools; Publications Office of the European Union: Ispra, Italy, 2019; pp. 11-53.

35. Tuz, A.A.; Simsek, A.K.; Kazanci, M. Production of organic nanoparticles by using nanoporous membranes. AIP Conf. Proc. 2017, 1809, 020048-1-020048-7.

36. Wuhrer, R.; Moran, K. Low voltage imaging and X-ray microanalysis in the SEM: Challenges and opportunities. IOP Conf. Ser-Mat. Sci. 2016, 109, 012019. [CrossRef]

37. Danino, D. Cryo-TEM of soft molecular assemblies. Curr. Opin. Colloid Interface Sci. 2012, 17, 316-329. [CrossRef]

38. Danaei, M.; Dehghankhold, M.; Ataei, S.; Davarani, F.H.; Javanmard, R.; Dokhani, A.; Khorasani, S.; Mozafari, M.R. Impact of particle size and polydispersity index on the clinical applications of lipidic nanocarrier systems. Pharmaceutics $2018,10,57$. [CrossRef]

39. Meegoda, J.N.; Hewage, S.A.; Batagoda, J.H. Stability of nanobubbles. Environ. Eng. Sci. 2018, 35, 1216-1227. [CrossRef]

40. Park, B.; Yoon, S.; Choi, Y.; Jang, J.; Park, S.; Choi, J. Stability of engineered micro or nanobubbles for biomedical applications. Pharmaceutics 2020, 12, 1089. [CrossRef]

41. Jang, G.Y.; Kim, M.Y.; Lee, Y.J.; Li, M.; Shin, Y.S.; Lee, J.; Jeong, H.S. Influence of organic acids and heat treatment on ginsenoside conversion. J. Ginseng Res. 2018, 42, 532-539. [CrossRef] 